\title{
IDENTIFICATION AND ASSESSMENT OF AGING-RELATED DEGRADATION OCCURRENCES IN NUCLEAR POWER PLANTS
}

\author{
IN-KIL CHOI $^{1 *}$, YOUNG-SUN CHOUN ${ }^{1}$, MIN KYU KIM ${ }^{1}$, JINSUO NIE ${ }^{2}$, JOSEPH I. BRAVERMAN ${ }^{2}$, and \\ CHARLES H. HOFMAYER ${ }^{2}$ \\ ${ }^{1}$ Korea Atomic Energy Research Institute \\ Daejeon, 305-353, Korea \\ ${ }^{2}$ Brookhaven National Laboratory \\ Upton, NY 11973-5000, USA \\ *Corresponding author. E-mail : cik@kaeri.re.kr
}

Received September 15, 2010

Accepted for Publication July 18, 2011

Aging-related degradation of nuclear power plant components is an important aspect to consider in securing the long term safety of the plant, especially the seismic safety, since the degradation of the components affects not only their seismic capacity but their response. This can cause a change in the seismic margin of a component and the overall seismic safety of a system. To better understand the status and characteristics of degradation of components in Nuclear Power Plants (NPPs), the degradation occurrences of components in the U.S. NPPs were identified by reviewing recent publicly available information sources and the characteristics of these occurrences were evaluated and compared to observations from the past. Ten categories of components that are of high risk significance in Korean NPPs were identified, comprising anchorage, concrete, containment, exchanger, filter, piping systems, reactor pressure vessels, structural steel, tanks, and vessels. Software tools were developed to expedite the review process. Results from this review effort were compared to previous data in the literature to characterize the overall degradation trends.

KEYWORDS : Aging, Component Degradation, Degradation Occurrence, Passive Components

\section{INTRODUCTION}

The seismic safety of existing NPPs can be improved by an increase of the seismic capacity of the dominant equipment or components. Since the relationship between the seismic capacity of the facilities and the seismic risk of a nuclear plant can be obtained by using a probabilistic safety assessment, an improvement of the seismic safety of existing NPPs can be achieved effectively. The Seismic Probabilistic Risk Assessment (SPRA) is an effective method for quantitatively estimating a plant level risk. This evaluation method can be used to perform Periodic Safety Reviews (PSRs) and license renewal application (LRA) reviews. In addition, it can also be used to enhance the seismic safety of a NPP. For example, in the case of increasing the seismic capacities of equipment that is significantly contributing to core damage, the Core Damage Frequency (CDF), possibly as a result of a more accurate estimation of the seismic fragilities, may be decreased by more than $50 \%$ [1]. On the other hand, the aging related degradation of structures, systems, and components (SSCs) can cause a reduction of seismic safety margin of individual components and systems. Finally, this leads to a reduction of plant level seismic safety and an increase of CDF. In order to develop a realistic evaluation of the seismic safety of a plant, the potential effects of age-related degradation on SSCs within a NPP should be considered.

Identification of degradation occurrences for seismic safety-related components was performed using publicly available documents related to the nuclear power industry, primarily in the US. The documents reviewed for this study, include Licensing Event Reports (LERs), US Nuclear Regulatory Commission (NRC) generic correspondences, documents related to license renewal activities, industry reports, NUREG reports, and BNL and other national lab reports. LERs are reports that must be submitted by NPP licensees to the NRC if certain potential problems occur: any event or conditions that occurred in the plant which resulted in a condition of the plant being seriously degraded or the plant being in an unanalyzed condition that significantly degraded plant safety. 
The prior research reported in NUREG/CR-6679 [2] collected and evaluated degradation occurrences for components in US NPPs over the period 1985 to 1997. Therefore, this study focuses on the more current period from 1997 to 2008. That way, there would not be any overlap and an assessment could be made for the current period and the results compared to the conclusions reached from the prior period.

The information of degradation occurrences for safety related structures and components was evaluated in order to identify the important aging characteristics, and finally a trending analysis was performed to make a comparison to the results of past aging studies and to secure the seismic safety of NPPs for their plant life time.

\section{COMPONENT SELECTION}

A list of applicable structures and components was developed in order to define the scope of the types of structures and components that should be reviewed for degradation occurrences. Similar to the study reported in NUREG/CR-6679 [2], which did not include active components, we determined that this list would cover only structures and passive components (SPCs), but not active components. Active components, such as pumps, valves, and electrical equipment, are components that must move or change their state in order to perform their intended functions, and can typically be monitored for aging effects by monitoring their performance. By monitoring pressure, flow, electrical signals, etc., the potential aging degradation of active components can be identified, while for passive components, the extent of aging is usually difficult to identify and may even go undetected. In addition, active components are usually subjected to periodic inspection, testing, and maintenance, where aging effects would be detected and corrected over time.

Reviewing the list along with the list of 18 SPCs described in NUREG/CR-6679[2], 10 categories of SPCs that are considered to be the most risk significant were identified for the scope of the degradation review to be included in this study as follows [3]:

1. Anchorage

2. Concrete

3. Containment

4. Exchangers

5. Filters

6. Piping systems

7. Reactor pressure vessels (RPVs)

8. Structural steel

9. Tanks

10. Vessels

The subcomponents in each of the ten categories are described below:

Anchorage: anchorage covers all structural components that serve as a connection between a concrete element and a piece of equipment. Anchorages include embedded anchors, expansion anchors, grout (used beneath baseplates), and steel embedments.

Concrete: the concrete category includes reinforced concrete buildings; water intake structures; pump houses; underground structures; concrete walls, floors, ceilings, mats, foundations; canals; fuel pools; pits; pedestals; prestressed concrete structures; and manholes. It also includes masonry walls and block walls.

Containment: containment is a special type of structure in NPPs used as a final barrier to prevent the release of radioactive materials to the environment following a postulated accident that may occur inside the containment. Therefore, the containment is not categorized as either concrete or structural steel components. The containment category includes the steel shell or concrete shell, prestressing system if applicable, penetrations, torus (if applicable), bellows, liners, and supports. The prestressing system includes tendons, tendon anchorages, and grease used in the tendon conduits to prevent degradation of the tendons.

Exchanger: the exchanger category includes steam generators, heat exchangers, condensers (including ice condensers used in the design of some US plants), and supports.

Filters: filters include mechanical \& HVAC - screens, separators, strainers, absorbers, relevant supports, and housings. It should be noted that the subcomponents for filters do not include regular maintenance items which that are examined or replaced on a regular basis.

Piping systems: piping systems include piping, underground piping, fittings, small bore piping \& tubing, sleeves, and pipe supports. Hydraulic or mechanical assemblies of snubbers are not considered since they are active components and subject to periodic inspection and maintenance if needed.

RPVs: subcomponents of reactor pressure vessels (RPVs) include the shell, internals, passive components for control rod drive mechanisms (CRDMs), and relevant supports. Although pressurized, RPVs are distinguished as an individual component from other vessels because of their unique and important roles in nuclear power plants.

Structural steel: the structural steel category includes steel frames, trusses, platforms, supports, bolts, nuts, studs, fasteners, liners, doors, covers, hatches, and support to all types of equipment.

Tanks: tanks are those vessels that are subject only to atmospheric pressure.

Vessels: vessels are pressurized and include subcomponent pressurizers, other pressurized vessels, and their supports.

Degradation occurrences included in this study do not necessarily correlate to the number of degraded elements at a specific plant and date. If several degraded elements are found at the same plant on the same date, they are grouped into one degradation occurrence if they are the same subcomponent. 


\section{REVIEW AND COLLECTION OF DEGRADATION DATA}

\subsection{Licensee Event Reports}

\subsubsection{Review Methodology}

Since this study had to be based on publicly available information, licensee event reports (LERs) were chosen to be one of the primary sources for review. The LERs were also selected as the primary source for the following reasons: standardized requirements in accordance with 10 CFR 50.73 [4], continuous in time, completeness of information, good coverage of significant events, well formatted, and easy accessibility.

Since January 1, 1984, an LER has been required by 10 CFR 50.73 to be submitted within 60 days after the occurrence of a significant event following an immediate notification (required by 10 CFR 50.72 [5]). Each LER and its revisions are generally required to address specific events and plant conditions. Unrelated events or conditions, including cases of the same or similar components but different causes or separate events/activities, should be reported in different LERs. Voluntary LERs are encouraged to be submitted even if the events are not required by 10 CFR 50.73 and other requirements, but are believed by the licensee to be safety significant. An LER may be canceled by letter provided that the cancellation has a sound and logical basis.

LERs are also required by 10 CFR 50.73 to contain a brief abstract; a clear, specific, and narrative description of the event; an assessment of the safety consequences and implications of the event; corrective actions; and references to any previous similar events. In addition, LERs start with a signed cover letter and usually have a very instructive title. Most LERs use NRC FORMs 366/ 366A/366B, which include information such as facility name, docket number, event date, LER number, report date, etc. Compared to other sources of information as described in NUREG/CR-6679[2], LERs have the advantage of information completeness and a rule-based format, which can facilitate automation in their processing.

The LERs used in NUREG/CR-6679 were processed through the Sequence Coding \& Search System (SCSS) that was created and is maintained for the NRC by the Nuclear Operations Analysis Center at the Oak Ridge National Laboratory (ORNL). This database system contains over 35,000 LERs from 1980 to 1997, of which NUREG/CR-6679 covered the period of 1985 to 1997. SCSS provides a searchable way to process the LERs. However, this system is not accessible anymore, which precludes its use in this search effort. Development of a system similar to SCSS would require a sizable effort beyond the available resources for this study. Therefore, the identification and review process of recent LERs will be based on the NRC Agency-wide Documents Access and Management System (ADAMS).

Using the advanced search method with "LER" as the document type field, a total of 4323 LERs had been found as of 04/16/2008 (many new documents including new LERs are constantly collected in the ADAMS system).

Instead of reviewing the input directly through the online ADAMS system, in-house tools were developed to expedite the review process. These tools were used to retrieve the 4323 HTML files, convert these HTML files to pure text files, and help review the LERs by color-coding different parts of the LERs [3].

\subsubsection{Result Assessment}

A total of 223 Degradation Occurrence Records (DORs) were identified from the LERs for the period of 1999 to 4/16/2008, including just a few from 1998 as well.

Figure 1 shows the distribution of the SPC degradation

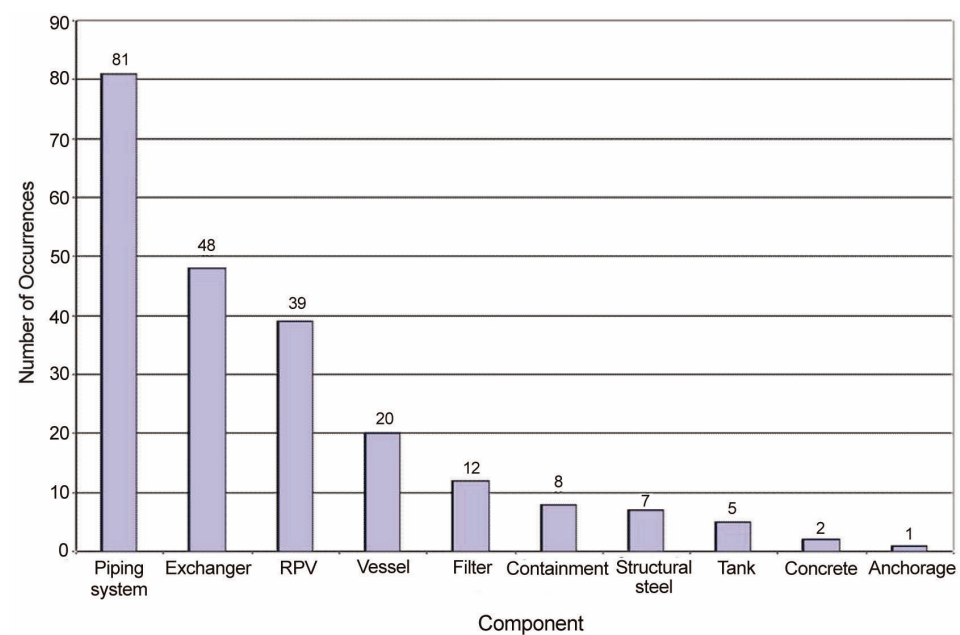

Fig. 1. Distribution of SPC Degradation Occurrences over Component Category 
occurrences by component categories, with the number of the degradation occurrences annotated over the bars. As would be expected, the piping systems have the most degradation occurrences reported in the LERs, about 36\% of the total DORs. Exchangers and RPVs have the next two largest number of degradation occurrences, representing about $22 \%$ and $17 \%$ of the total DORs, respectively. The other seven component categories represent less than 25\% of the total DORs; they are vessels, filters, containments, structural steel, tanks, concrete, and anchorage in descending order of the number of degradation occurrences. It should be noted that the number of degradation occurrences for a particular category is also a function of the quantity of components in that category that is present at a plant. Thus for example, the number of degradation occurrences for piping was expected to be large, because there are many piping systems at a NPP and many of these piping systems can be quite long.

The total number of DORs for structural type components, i.e., containments, structural steel, concrete, and anchorages, was only 18 , about $8 \%$ of all DORs. However, this does not necessarily indicate that there have been fewer degradations occurring in these structures. Rather, it is because of the nature of the structural degradation and the nature of the LER reporting requirement that are judged to result in fewer instances of degradation. As described previously, LERs report any degradation situations that seriously affect the plant safety or result in any unanalyzed conditions that could significantly compromise the plant safety. The events reported in LERs are often from operating experiences. Structural degradations usually have less immediate impact on plant safety, and therefore, are less likely to be observed and reported in LERs. However, structural degradations can be significant risk factors to plant safety when a severe environmental event, for example, a large earthquake, occurs. Most structural degradations can be found in literature that involved results from special inspection efforts. For example, NUREG-1522 covers data obtained from walkdowns conducted at six older vintage plants [6].

\subsubsection{Trending Analysis}

To evaluate the possible trends in degradation occurrence data, the DORs in the past decade (approximately 1999 to 2008 collected in this study) and those reported in NUREG/CR-6679 [2] (approximately 1985 to 1997) were compared. In order to make a sound comparison, a few differences between the current data collection using the recent LERs and those reported in NUREG/CR-6679 should be noted. These are highlighted in the following:

1. Difference in Information Sources: unlike the current set of data collected in this study, which relies on LERs 1999-2008, NUREG/CR-6679 covered a larger set of information sources, which included LERs 1985-1997, NUREGs, NRC/IE Information notices,
Correspondence, Generic Letters, NRC Bulletins, IR Circulations, SECY documents, and other publicly available documents.

2. Difference in LER retrieval methods: one-by-one evaluation for LER 1999-2008 versus computer based search for LER 1985-1997 through SCSS at ORNL.

3. Difference in component lists: 10 component categories for the current collection versus 18 component categories for NUREG/CR-6679.

4. Difference in subcomponent lists: all SPCs for the current collection versus the reduced scope for NUREG/CR-6679 (e.g., piping, fittings, small bore piping and tubing, sleeves, penetrations, etc.).

These differences were considered in the comparisons presented in the trending analysis. Hereafter, for consistency with the data collected in this study, the various comparisons use either the original data from NUREG/CR-6679, which includes all sources, or only those related to LER 19851997. The corresponding labels in this paper's figures are self-explained regarding their information sources.

Figure 2 shows the distributions of the degradation occurrences by components for three series of data: LER 1999-2008, NUREG/CR-6679, and LER 1985-1997, respectively. The bar chart is in the same order as reported in NUREG/CR-6679. Similarly, Figure 3 shows a normalized version of the same figure with the total numbers of DORS in each series as the basis. Considering LER 1999-2008 and NUREG/CR-6679, exchangers, piping systems, and RPVs are the first three categories with the greatest number degradation occurrences. Since the DORs for piping systems for LER 1985-1997 were very large and did not include all of the occurrences in the SCSS database, the actual number of DORs for piping systems for LER 1985-1997 are artificially low. These figures also show that filters were the second largest category using LER 1985-1997. Both LER data series confirm the observation in the previous section that LERs do not report many structural DORs, especially containment, concrete, and anchorage.

Figure 4 shows the distribution comparison of the SPC degradation occurrences over time, with the top figure showing the two series from NUREG/CR-6679 and with the bottom figure showing the series representing LER 1999-2008. First of all, the strong correlation over the years between the two series from NUREG/CR-6679 indicates that LER 1985-1997 represents a significant portion of the NUREG/CR-6679 data. Regardless of the partial years 1997, 1998, and 2008, the yearly DORs vary somewhat in cycles, which might correspond to inspection intervals that often are scheduled at refueling or are required by special NRC mandatory inspection requirements. On a yearly basis, there appear to be slightly more DORS from LER 1998-2008 than from LER 1985-1997. This observation may be due to the difference in reviewing LERs; the computer search 


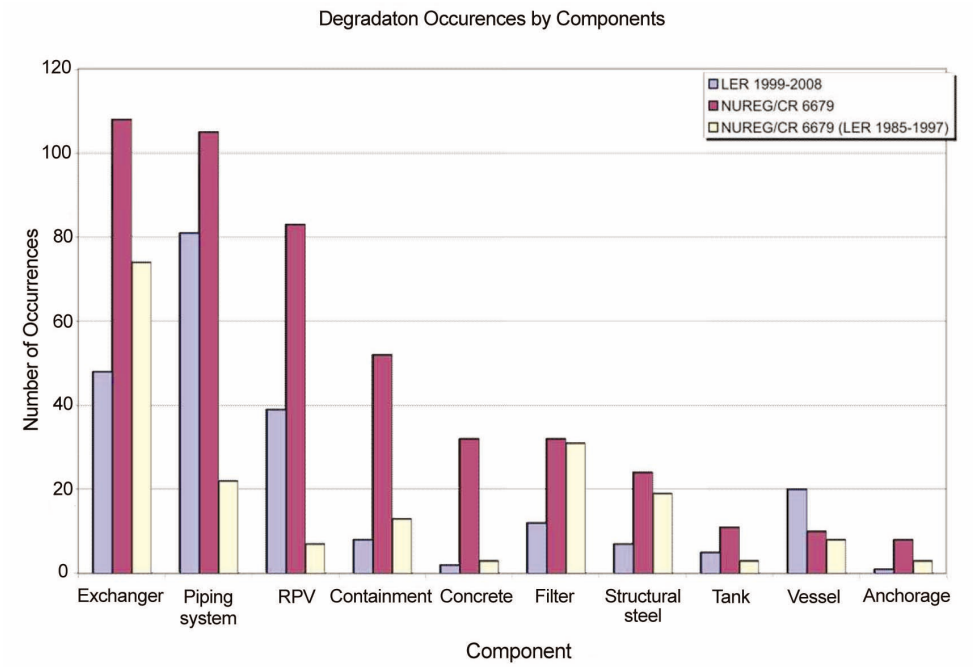

Fig. 2. Distribution Comparison of SPC Degradation Occurrences over Component

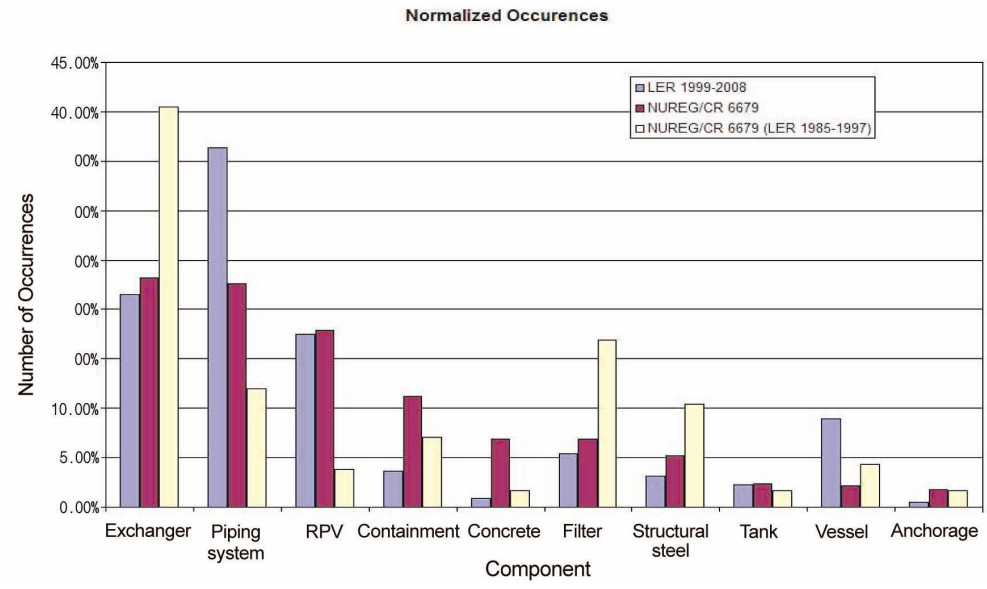

Fig. 3. Comparison of Normalized Distribution of SPC Degradation Occurrences over Component
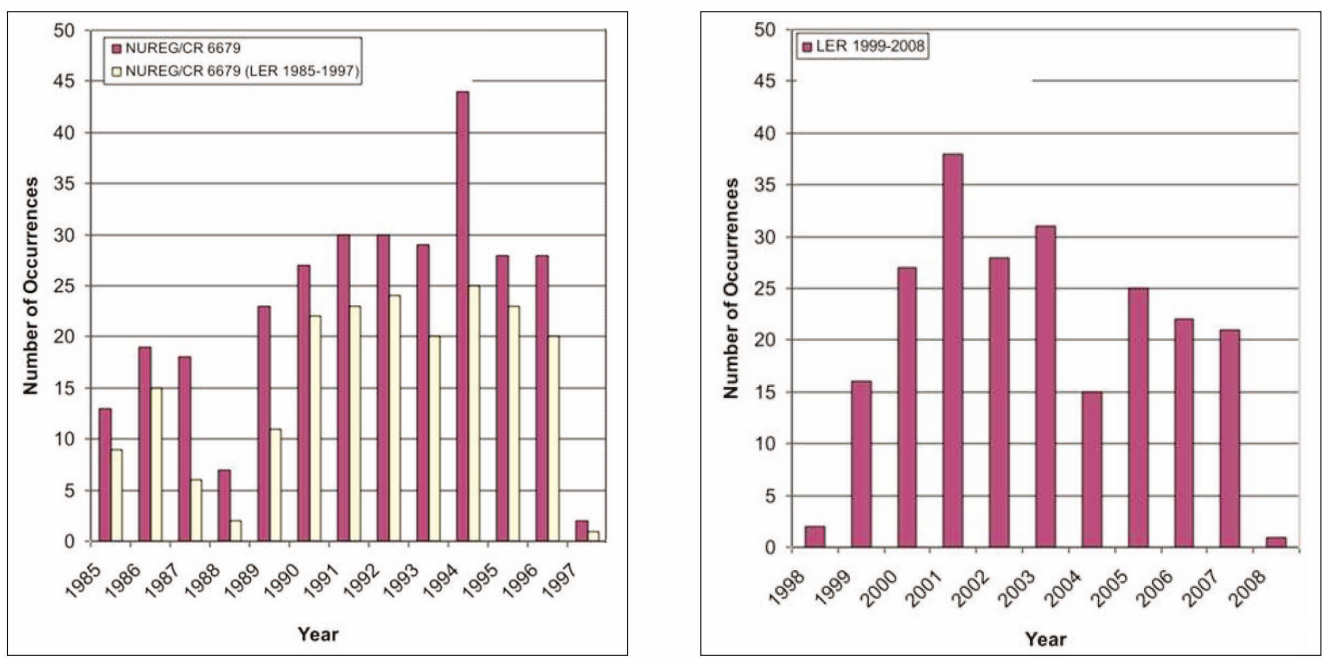

Fig. 4. Distribution Comparison of SPC Degradation Occurrences over Time 
approach for LER 1985-1997 may not have the same level of coverage of the degradation population as the one-by-one review approach for LER 1999-2008.

Excluding the three partial years, DORs from LER 1985-1996 and LER 1999-2007 are correlated to their plant ages at event (PAAE), which is defined as (Event Date - CP Issued Date). Table 1 and Table 2 show the number of DORs and the number of NPP units that these DORs belong to as a function of PAAE for LER 19992007 and LER 1985-1996, respectively. Taking the row of a PAAE equal to 33 as an example, it shows that there were 20 NPP units that had 30 DORs at the time that these units were 33 years old as defined by the PAAE. The fourth columns in these two tables list the average number of DORs that were obtained by dividing the number of DORs by the number of affected NPP units.

Figure 5 presents the number of DORs and the number of associated NPP units distributed over the PAAE. For

Table 1. Number of DORs and NPP Units by PAAE for LER 1999-2007

\begin{tabular}{|c|c|c|c|}
\hline \multicolumn{4}{|c|}{ LER 1999-2007 } \\
\hline PAAE & DORs & NPP Units & DORs/NPP Units \\
\hline 23 & 2 & 2 & 1.000 \\
\hline 24 & 4 & 4 & 1.000 \\
\hline 25 & 3 & 3 & 1.000 \\
\hline 26 & 11 & 9 & 1.222 \\
\hline 27 & 10 & 9 & 1.111 \\
\hline 28 & 11 & 10 & 1.100 \\
\hline 29 & 10 & 8 & 1.250 \\
\hline 30 & 11 & 7 & 1.571 \\
\hline 31 & 21 & 15 & 1.400 \\
\hline 32 & 19 & 14 & 1.357 \\
\hline 33 & 30 & 20 & 1.500 \\
\hline 34 & 22 & 12 & 1.833 \\
\hline 35 & 18 & 15 & 1.200 \\
\hline 36 & 16 & 14 & 1.143 \\
\hline 37 & 10 & 10 & 1.000 \\
\hline 38 & 7 & 5 & 1.400 \\
\hline 39 & 6 & 5 & 1.200 \\
\hline 40 & 7 & 5 & 1.400 \\
\hline 41 & 5 & 4 & 1.250 \\
\hline
\end{tabular}

both data series LER 1985-1996 and LER 1999-2007, the distributions show central peaks at 24 years and 33 years (PAAE), respectively, on curves related to DOR distribution and NPP unit distribution. These peaks and the hill shape distributions may suggest the distribution of construction time of the U.S. NPP population. As the two data series are separated by approximately 10 years, the associated curves show similar shifts, in particular with the peaks separated by 9 years. It is important to note that the upward shift between the two series shows the increase of the numbers of DORs and the affected units, indicating increasing age-related degradations. The peaks increase from 22 to $30(36 \%)$ for the number of DORs and from 15 to 20 (33\%) for the number of affected NPP units. The overall shift in the hill shape appears to represent linear increases in the numbers of DORs and affected NPP units. It should be noted that the smaller

Table 2. Number of DORs and NPP Units by PAAE for LER 1985-1996

\begin{tabular}{|c|c|c|c|}
\hline \multicolumn{4}{|c|}{ LER 1985-1996 } \\
\hline PAAE & DORs & NPP Units & DORs/NPP Units \\
\hline 8 & 1 & 1 & 1.00 \\
\hline 12 & 3 & 3 & 1.00 \\
\hline 13 & 2 & 2 & 1.00 \\
\hline 14 & 5 & 4 & 1.25 \\
\hline 15 & 4 & 3 & 1.33 \\
\hline 16 & 11 & 10 & 1.10 \\
\hline 17 & 11 & 10 & 1.10 \\
\hline 18 & 12 & 9 & 1.33 \\
\hline 19 & 9 & 8 & 1.13 \\
\hline 20 & 11 & 11 & 1.00 \\
\hline 21 & 11 & 10 & 1.10 \\
\hline 22 & 13 & 10 & 1.30 \\
\hline 23 & 8 & 8 & 1.00 \\
\hline 24 & 22 & 15 & 1.47 \\
\hline 25 & 15 & 11 & 1.36 \\
\hline 26 & 10 & 9 & 1.11 \\
\hline 27 & 8 & 7 & 1.14 \\
\hline 28 & 6 & 6 & 1.00 \\
\hline 29 & 8 & 6 & 1.33 \\
\hline 30 & 1 & 1 & 1.00 \\
\hline
\end{tabular}


numbers of DORs and affected NPP units at a higher PAAE than the peak PAAE do not indicate there were fewer degradations for older plants, rather there were a smaller number of older plants in the operating NPP fleet. A similar observation occurs for the lower PAAE because there were fewer relatively younger plants during the 1999-2007 review periods.

Figure 6 shows the numbers of DORs and the associated NPP units with the two data series combined. The combination was achieved by adding the related numbers for the overlapped PAAEs. The trend lines considered data up to a PAAE of 36 years, which was selected because shortly after this PAAE, the number of DORs and plants drops off rapidly, which if included would skew the resulting trend lines. The trend lines show that both the number of DORs and the numbers of associated NPP units increase as the PAAE increases. In addition, the increase in the number of DORs rises faster than the increase in the number of NPP units.

Figure 7 shows the relation of the average degradation

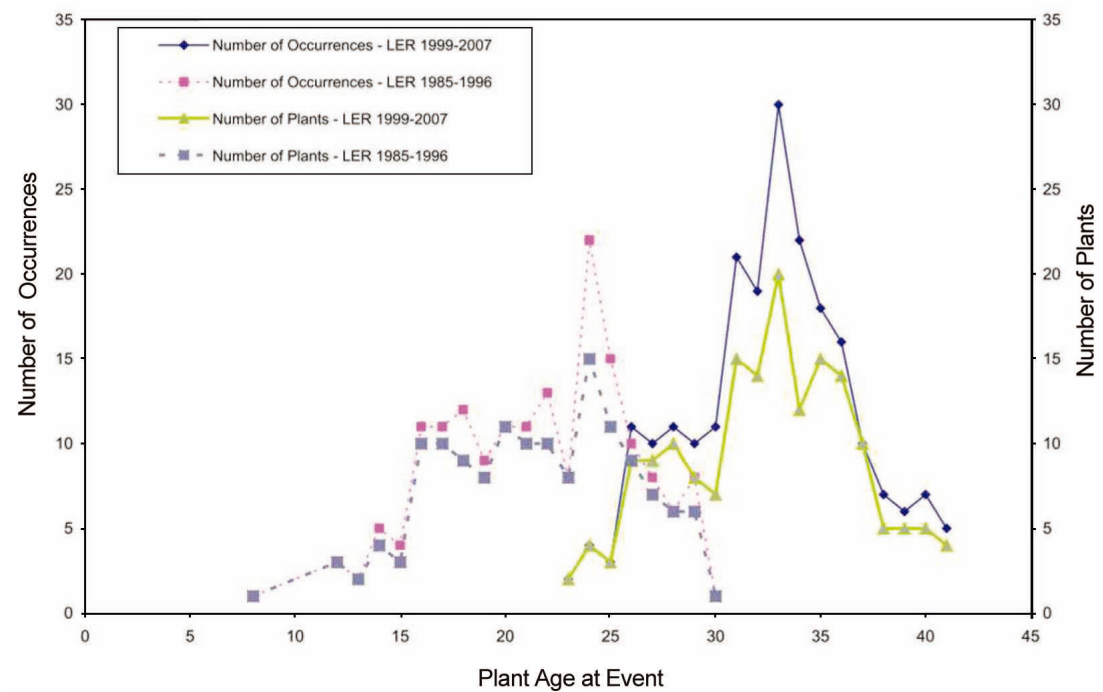

Fig. 5. Number of Degradation Occurrences and NPP Units with Plant Age at Event

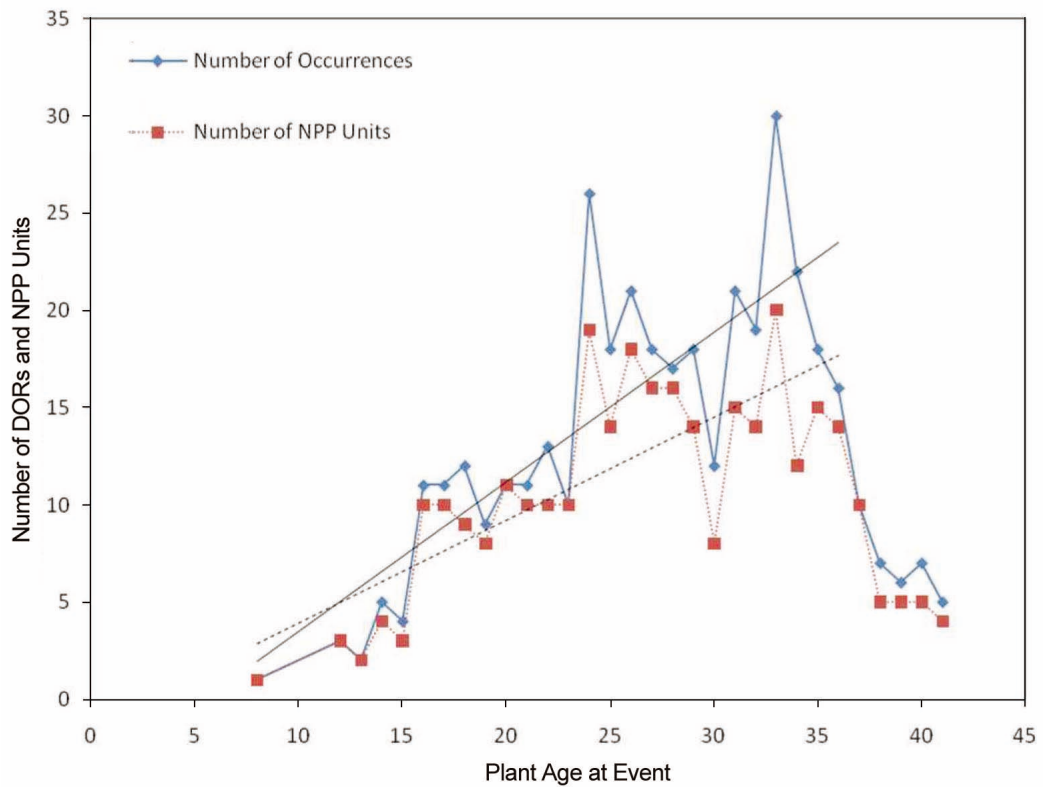

Fig. 6. Number of Degradation Occurrences and NPP Units with PAAE for Combined Data Series 


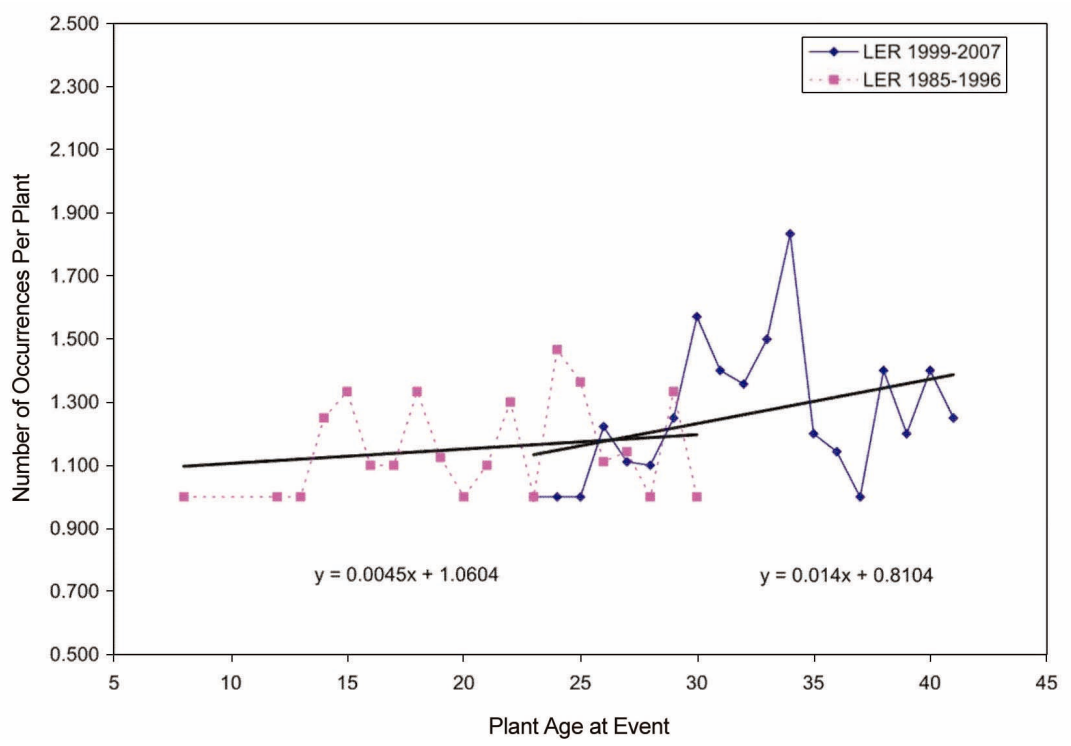

Fig. 7. Average Degradation Occurrences with Plant Age at Event

occurrences with the PAAE. As an example, the peak point in this figure shows that for plants at the age of 34 years, about 1.8 DORs per plant were reported in LERs. The dotted line designates the series LER 1985-1996 while the solid line represents the series LER 1999-2007. It appears that the average number of DORs per plant increases as the plant gets older, with a slightly higher rate for older plants as shown by the steeper slope using LER 1999-2007. The slightly higher degradation rate using more recent LERs reflects the fact that older plants show in general more degradation occurrences, and may reflect as well the lowered coverage of the possible degradation population by limiting the number of DORs in NUREG/CR-6679 (e.g. piping system) and potentially by using the computerize search approach for LER 19851997. By literally reading the two trend lines, the older plants (using LER 1999-2007) appear to have about 3 times high rate (slope of the trend line) of the average DORs than the younger plants (using LER 1985-1997); however, this observation may not fully represent the real situation because of the differences in processing the two LER series. In addition, this observation may not be true for structural type components, as the data from LERs are less representative of the structural components. The variations in these two curves are judged to be relatively large due to the fact that these degradations are rare events and the number of DORs is relatively small.

Figure 8 shows the relationship of the average DORs per plant to the PAAE using the combined data series. The trend line in Figure 8 shows that combining the two series results in a slightly increasing average degradation per plant over the PAAE and is essentially an average of the prior two trend lines shown in Figure 7.

Figure 9 shows the comparison for the distributions of the SPC degradation occurrences with respect to major aging effects among the three data series for steel components (more precisely metal components). Cracking is the most predominant aging effect for all three data series. Failure is the second most significant aging effect for LER 19982008 because it includes a number of aging effects that do not fall into any listed categories. DORs with aging effects of loss of material and wall thinning appear to be obtained from information sources other than LERs.

Figure 10 shows the comparison of the distributions of the SPC degradation occurrences by major aging mechanisms among the three data series. SCC is the most significant aging mechanism for all the data series. Compared to the two NUREG/CR-6679 data series, LER 1999-2008 shows a large DOR contribution from fatigue, which is the second most significant degradation for this series. This may be due to the possibility that some components are approaching their fatigue life as NPPs get older. Moisture, organisms, chemical attack, and foreign objects are shown to be less important mechanisms for LER 1998-2008; lessons learned from the past may have helped to avoid such aging mechanisms.

Figure 11 shows the comparison of the distributions of the SPC degradation occurrences by cracking type among the three data series. Primary water stress corrosion cracking (PWSCC) is the most common cracking type for both LER data series, partly indicating the preferences of the LER reporting system. On the other hand, intergranular stress corrosion cracking (IGSCC) was found to be the most common cracking type for the NUREG/CR-6679 


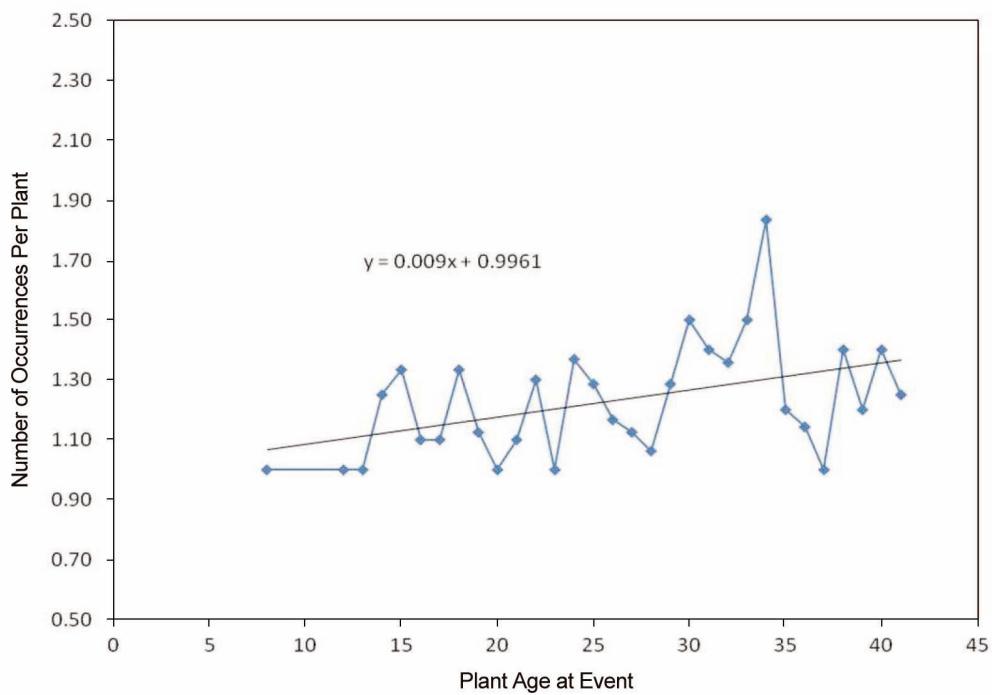

Fig. 8. Relation of Average DORs per Plant versus PAAE with Combined Data Series

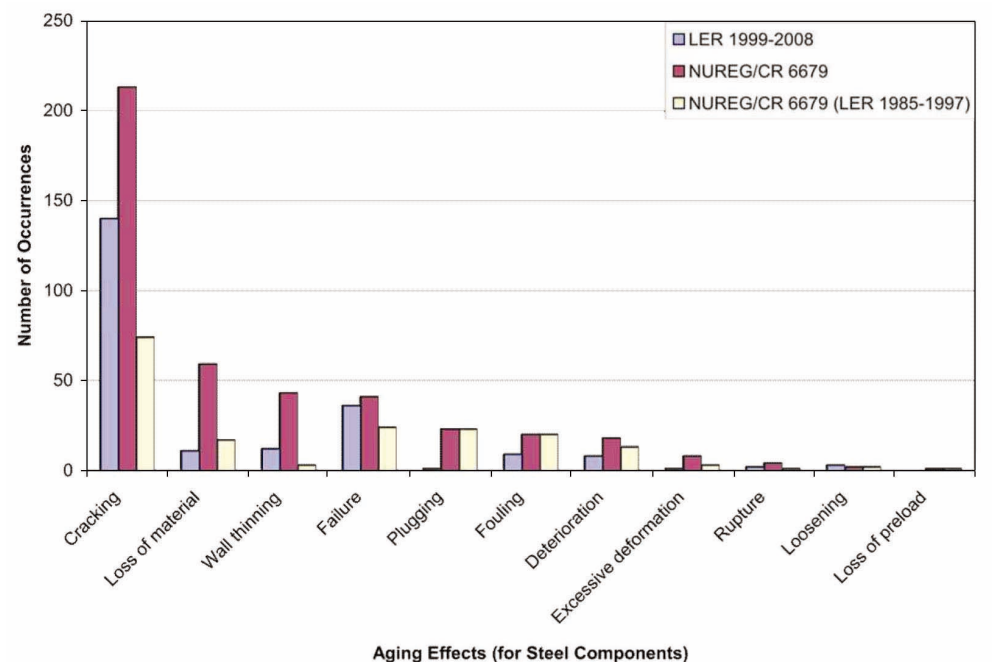

Fig. 9. Distribution Comparison of SPC Degradation Occurrences over Aging Effect (for Steel Component)

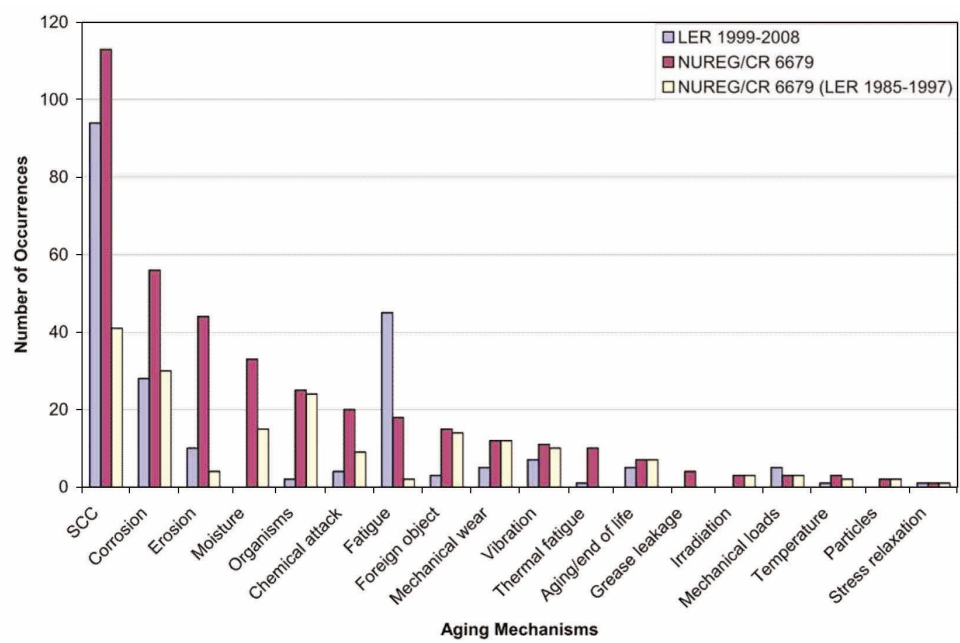

Fig. 10. Distribution Comparison of SPC Degradation Occurrences over Aging Mechanism 


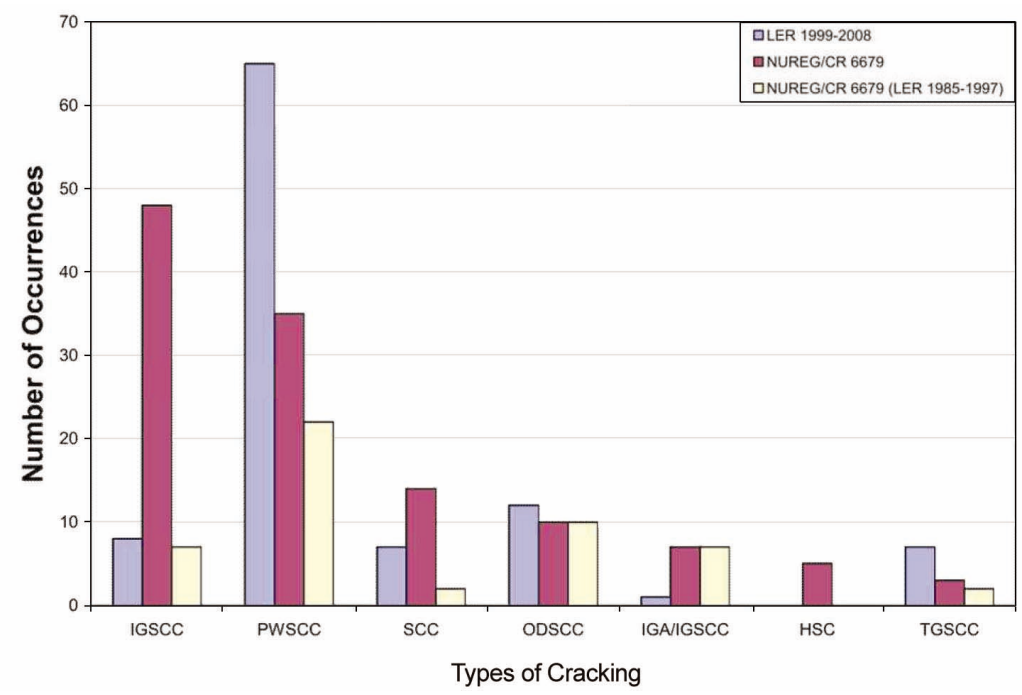

Fig. 11. Distribution Comparison of SPC Degradation Occurrences over Cracking Type (IGSCC (Intergranular Stress Corrosion Cracking), PWSCC (Primary water SCC), ODSCC (Outer Diameter SCC), IGA (Intergranular Attack), IGSCC (Intergranular SCC), HSC (Hydrogen Stress Corrosion), TGSCC (Transgranular SCC))

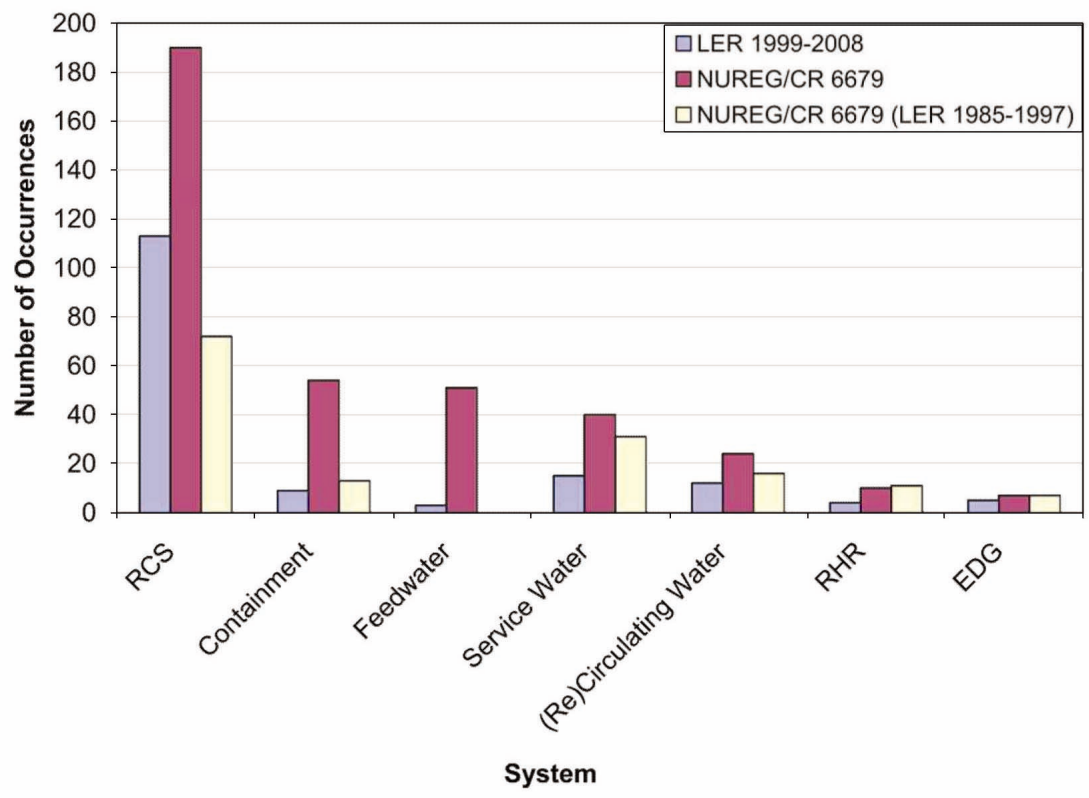

Fig. 12. Distribution Comparison of SPC Degradation Occurrences over System (RCS (Reactor Coolant System), RHR (Residual Heat Removal), EDG (Emergency Diesel Generator))

data series, but it was a much less common cracking type for the other two LER data series. This suggests that other information sources provided those extra IGSCC DORs for the NUREG/CR-6679 data series.

Figure 12 shows the comparison of distributions of the SPC degradation occurrences by system types among the three data series. It is obvious using all series that the system most vulnerable to degradation is the reactor coolant system (RCS), as expected because the RCS includes many subcomponents that are constantly subjected to harsh environments such as high temperature, high pressure, high fluid velocity, boron acid, radiation, etc. 


\subsection{Generic Communication and LRAs}

In addition to recent LERs, selected generic communications and license renewal applications (LRAs) were also reviewed to identify the characteristics of the age-related degradation of structures and passive components (SPC). Generic communications reviewed included Generic Letters (GL), Bulletins (BL), and Information Notices (IN) issued by the US NRC. Since these documents may not include all information needed for the degradation occurrence record (DOR) or may include duplicate DORs with respect to LERs, the findings are not incorporated into the same DOR tables described in Section 3 of this paper. Therefore, the degradation information obtained from NRC generic communications is evaluated and described separately in this section.

LRAs were also reviewed under this study because they provide useful information about aging degradation of SPCs. These applications are required to include information about aging by regulations (10 CFR 50.73[4]) which cover the submittal of LRAs. These regulations specifically require applicants to describe their operating experience regarding age-related degradation for the various SPCs.

\subsubsection{Generic Letters, Information Notices, and Bulletins}

Generic communications are publicly available documents through the NRC web site. Generic communications are the NRC's primary method of communicating a common need or resolution approach to an issue or providing guidance on issues pertaining to a matter of regulatory interest. Generic communications also allow the NRC to communicate and share industry experiences and send information to specific classes of licensees and interested stakeholders. The type of generic communication issued is determined during $\mathrm{NRC}$ evaluations of the operating nuclear industry and regulatory activities. Once issued, a generic communication is placed in ADAMS as an official NRC record.

Three types of generic communications were reviewed in this study. They consist of Generic Letters (GLs), Bulletins (BLs), and Information Notices (INs). GLs are NRC communications to licensees for the purpose of transmitting important information and usually require action or response. BLs address significant issues of great urgency and usually require action or response. INs relate to safety, safeguards, or environmental issues on which licensees consider action as appropriate.

Similar to the review effort of LERs, the focus in this study was on recent GLs, BLs, and INs, within the general time periods of 1997 through the first part of 2008. Since degradation occurrences did not occur or were not identified on the NRC web site for some of these years, the actual periods of degradation were 1997 to 2006 for GLs, 2001 to 2004 for BLs, and 1998 to 2007 for INs. All of the generic communications during these periods were reviewed to identify and document aging degradation for the ten categories of structures and passive components (SPCs) listed in Section 3.1. Document titles were instructive in determining which documents should be retrieved for more careful review. A total of 46 generic communication documents were reviewed, including $7 \mathrm{GLs}, 6 \mathrm{BLs}$, and 33 INs.

Table 3 summarizes for each type of generic communication the number of generic communications that address a particular component / subcomponent, and Table 4 aggregates the results in Table 3 by removing the types of generic communications. It should be noted that the number of generic communications addressing a component is different from the number of degradation occurrences because one generic correspondence may refer to multiple events with regard to one component. As can be seen from Table 4, steam generators (exchangers), RPVs, and piping systems are the top three components with the greatest number of generic correspondences, which are about $28 \%, 28 \%$, and $15 \%$ of the total 46 documents. Although these numbers do not equal what have been found using LERs as described in Section 3, for the reasons stated above, they constitute a total of $71 \%$, which is very similar to the $75 \%$ found in Section 3. There are six generic correspondences on structural type components (containment, concrete, spent fuel pools), which is about $13 \%$ of the total number of reviewed generic correspondences. This ratio is just slightly higher than the $8 \%$ as determined in Section 3, indicating that generic communications addressed more structural type components.

In summary, the results of the review of generic letters generally confirm what was found or explained in Section 3 for LER evaluations.

\subsubsection{License Renewal Applications}

License Renewal Applications (LRAs) were also reviewed under this study because they provide useful information about aging degradation of SPCs. These applications are required to include information about aging by regulations which cover the submittal of LRAs. These regulations specifically require applicants to describe their operating experience regarding age-related degradation for the various SPCs.

The Atomic Energy Act and NRC regulations limit commercial power reactor licenses to an initial 40 years but also permit such licenses to be renewed. This original 40 -year term for reactor licenses was based on economic and antitrust considerations - not on limitations of nuclear technology. Due to this selected period, however, some structures and components may have been engineered on the basis of an expected 40-year service life. Since the expense of design and construction of NPPs has been so great, it is generally much more cost effective to extend the operating life of a NPP beyond the 40-year license 
given to plants. Therefore, the NRC has established a timely license renewal process and clear requirements for renewing the operating license of NPPs. These requirements are codified in 10 CFR Part 54 [7], "Requirements for Renewal of Operating Licenses for Nuclear Power Plants" and 10 CFR Part 51 [8], "Environmental Protection Regulations for Domestic Licensing and Related Regulatory Functions." These requirements assure safe plant operation for the extended plant life. When approved, the renewal of license is granted for an additional 20 years.

Documents related to LRAs are useful because they identify applicable aging effects and operating experience describes aging degradation of structures and components at the plants. At the NRC website, there were 24 completed (reviewed and approved) applications for license renewal. These are presented below.

For each Aging Management Program (AMP) included in an LRA, there is an "Operating Experience" discussion
Table 4. Summary of Degradation by Components

\begin{tabular}{c|c}
\hline Component & $\begin{array}{c}\text { Number of Generic } \\
\text { Correspondences }\end{array}$ \\
\hline Steam Generators & 13 \\
\hline RPV & 13 \\
\hline Piping & 7 \\
\hline Strainer - Sump Pump Screens & 3 \\
\hline Pressurizer & 3 \\
\hline Containment & 3 \\
\hline Concrete & 2 \\
\hline Spent Fuel Pool & 1 \\
\hline Equipment - boric acid leakage onto & Total $=46$ \\
\hline
\end{tabular}

Table 3. Summary of Degradation Information by Generic Communications

\begin{tabular}{|c|c|c|}
\hline Generic Correspondence & Component / Subcomponent & $\begin{array}{l}\text { Number of Generic Correspondences on } \\
\text { this Component }\end{array}$ \\
\hline \multirow[t]{4}{*}{ Generic Letter } & Steam Generators & 4 \\
\hline & Strainer - Sump Pump Screens & 2 \\
\hline & RPV - CRD nozzles \& other penetrations & 1 \\
\hline & & Subtotal $=7$ \\
\hline \multirow[t]{4}{*}{ Bulletin } & RPV - head penetrations and coolant boundary & 4 \\
\hline & Strainer - Sump Pump Screens & 1 \\
\hline & Pressurizer and steam space piping connection & 1 \\
\hline & & Subtotal $=6$ \\
\hline \multirow[t]{10}{*}{ Information Notice } & Steam Generators & 9 \\
\hline & RPV - nozzles & 8 \\
\hline & Piping & 7 \\
\hline & Containment & 3 \\
\hline & Concrete & 2 \\
\hline & Pressurizer & 2 \\
\hline & Spent fuel pool - liner & 1 \\
\hline & Equipment - boric acid leakage onto & 1 \\
\hline & & Subtotal $=33$ \\
\hline & & Total $=46$ \\
\hline
\end{tabular}


that is very informative for aging-related degradation review. However, the information presented in these operating experience discussions is not as detailed as in the LERs.

At the NRC website, there are 24 completed (reviewed and approved) applications for license renewal. There were also 12 LRAs under review at the time that this study was performed. Since each LRA is quite large and the total number of LRAs were too numerous to review in the current study, two LRAs were selected for review in this study. The criteria used for selection of the two LRAs are (1) one of each PWR and BWR, (2) recent LRA - more likely to reflect knowledge gained from prior LRA submittals and comments from the NRC, (3) more complete information on operating experience, and (4) more detailed. Using these criteria, the two LRAs selected were Palisades (PWR) and Point Beach Units 1 \& 2 (BWR). Detailed review of these two LRAs included summaries of the Aging Management Program and operating experiences that covered industry-wide observations and plant specific issues. The review of these LRAs qualitatively showed that degradation in components related to piping systems, RPVs, and exchangers occurred more often than the other components being studied. This observation is consistent with the results from the review of LERs as expected because the industry and plant-specific operating experiences on aging in the LRAs were most likely already in the LERs that the plant(s) submitted in the past.

\section{CONCLUSIONS}

A survey of degradation occurrences for structures and passive components (SPCs) was conducted using recent licensee event reports (LERs); recent generic letters, bulletins, and information notices; and license renewal applications. The study also included a trending analysis of the degradation occurrence records (DORs) obtained from LERs, in combination with data reported in NUREG/CR6679. The goal of this study was to identify any new degradation trends and to determine whether the findings reported in NUREG/CR-6679 still hold.

The results of this study demonstrated that piping systems have the most degradation occurrences reported in LERs, about $36 \%$ of the total DORs. Exchangers and RPVs have the next two largest numbers of degradation occurrences, representing about $22 \%$ and $17 \%$ of the total DORs, respectively. The other seven component categories represent less than $25 \%$ of the total DORs. It should be noted that part of the explanation for these results is related to the number of components that are found at a NPP.

Cracking was found to be the most predominant aging effect. Stress corrosion cracking (SCC) was the most significant aging mechanism for all three data series. The system that was most vulnerable to degradation was the reactor coolant system (RCS), as expected, because the RCS includes many subcomponents that are constantly subjected to harsh environments such as high temperature, high pressure, high fluid velocity, boron acid, radiation, etc.

Review of recent generic communications indicated that exchangers, RPVs, and piping systems are the top three components that generic correspondences address. Generic communications discuss more structural type components than the LERs do. Regarding aging-degradations, the information presented in LRAs is not as detailed as that in the LERs. These reviews did not yield adequate data for a direct comparison to those found using LERs. However, these reviews confirmed qualitatively the findings using LERs, because in many cases the plantspecific information in the LRAs, for the more significant degradation occurrences, was already in the LERs for that plant.

The trending analysis confirmed that the patterns of degradation occurrences have not significantly changed from past studies, although signs of a slight increase in the number of DORs have been observed. Structural degradations are expected to be a factor as plants age and are important to plant safety when extreme environmental demands such as large earthquakes are considered.

\section{DISCLAIMER NOTICE}

The findings and opinions expressed in this paper are those of the authors and do not necessarily reflect the views of Korea Atomic Energy Research Institute or the Brookhaven National Laboratory.

\section{ACKNOWLEDGEMENT}

This research was supported by the Mid- and LongTerm Nuclear Research \& Development Program of the Ministry of Education, Science and Technology, Korea.

\section{REFERENCES}

[1] Young-Sun Choun, In-Kil Choi, and Jeong-Moon Seo, "Improvement of the Seismic Safety of Existing Nuclear Power Plants by an Increasing of the Component Seismic Capacity: A Case Study," Nuclear Engineering and Design, 238, pp. 1410-1420, 2008.

[2 ] Braverman, J.I., Hofmayer, C.H., Morante, R.J., Shteyngart, S., and Bezler, P., Assessmesnt of age-related degradation of structures and passive components for U.S. nuclear power plant, Brookhaven National Laboratory, NUREG/CR6679 , July 2000.

[ 3 ] Nie, J., Braverman, J., and Hofmayer, C., Choun, Y.S., Kim M.K., and Choi, I.K, Identification and Assessment of Recent Aging-Related Degradation Occurrences in U.S. Nuclear Power Plants, BNL Report-81741-2008 and KAERI/RR-2931/2008, 2008.

[4] U.S. Nuclear Regulatory Commission, 10 CFR 50.73, Licensee Event Report System.

[5] U.S. Nuclear Regulatory Commission, 10 CFR 50.72, Immediate Notification Requirements for Operating Nuclear Power Reactors. 
[ 6] H. Ashar and G. Bagchi, Assessment of Inservice Condition of Safety-Related Nuclear Plant Structures, U.S. Nuclear Regulatory Commission, NUREG-1522, Washington, D.C., June 1995.

[7] U.S. Nuclear Regulatory Commission, 10 CFR Part 54,
Requirements for Renewal of Operating Licenses for Nuclear Power Plants.

[8 ] U.S. Nuclear Regulatory Commission, 10 CFR Part 51, Environmental Protection Regulations for Domestic Licensing and Related Regulatory Functions. 